\title{
Dengue Viruses Activity in Piauí, Brazil
}

\author{
José Adail Fonseca de Castro/ ${ }^{+}$, Hélida Monteiro de Andrade, \\ Semiramis Jamil Hadad do Monte, Adalberto Socorro da Silva, \\ Karlla Celma Batista Lima Gomes, Leila Fernandes de Brito e Amaral, \\ Flávio de Oliveira Cipriano, Juciane Vaz do Rego, Marcos Antônio da Mota Araújo, \\ Symonara Karina Medeiros Faustino*, Rita Maria Ribeiro Nogueira**, \\ Hermann Gonçalves Schatzmayr**, Marize Pereira Miagostovich**
}

\begin{abstract}
Laboratório de Imunogenética e Biologia Molecular, Departamento de Parasitologia/Microbiologia, Universidade Federal do Piauí, Campus Petrônio Portela, Bloco 16, 64049-550 Teresina, PI, Brasil *Laboratório Central do Estado do Piauí, Teresina, PI, Brasil

**Laboratório de Flavivirus, Departamento de Virologia, Instituto Oswaldo Cruz-Fiocruz, Rio de Janeiro, RJ, Brasil
\end{abstract}

The present paper reports a laboratory investigation performed between the years of 2000 and 2002 to stydy a virological surveillance program introduced in the state of Piaui to support an epidemiological survey of the disease. Dengue virus type 3 (DENV-3) existence in the state was detected in May 2002 when a high number of dengue cases due to DENV-1 and DENV-2 were reported. An assessment on the population knowledge about the disease and its transmission showed that almost 50\% of the population were still unaware of the epidemiological features of dengue.

Key words: dengue viruses - Piauí - Brazil

Dengue is an acute viral disease caused by any of four types ( 1 to 4 ) of dengue virus (DENV), mainly transmitted by the mosquito Aedes aegypti, being considered the most important re-emergent infectious disease with more than 50 million people infected annually in the world-wide (Gubler 2002).

In the Americas, the emergence of epidemic was well recognized from the 80 's when the first outbreak of dengue hemorrhagic fever/dengue shock syndrome (DHF/DSS) occurred in Cuba (Pinheiro \& Coubert 1997). Nowadays, all of the four serotypes have been reported and the hiperendemicity may be characterized in many countries of American continent (Gubler 1998).

In Brazil, the co-circulation of DENV-1 and DENV-2 in 26 states resulted in more than 2,3 million cases notified until 2001, increasing the severity of the disease (Nogueira et al. 1993, 2002, Zagne et al. 1994). In 2002, a number of 758,000 cases were reported representing $75 \%$ of the reported cases in the American continent, which has been attributed to the introduction of DENV-3 in the country (Nogueira et al. 2001, www.paho.org/english/HCP/HCT/ VBD/dengue-cases-2002.htm).

In the Northeast region of the country, including the state of Piauí and other eight states, dengue became a public health problem since the early 90's when the

Financial support: $\mathrm{CNPq}$ and Fiocruz

${ }^{+}$Corresponding author. Fax: +55-86-215.5690. E-mail: libpi@ufpi.br

Received 12 August 2003

Accepted 29 October 2003 outbreaks of the disease become more frequent. In 1998, that region, specially comprising the states of Ceará, Bahia, Alagoas, and Pernambuco, was responsible for more than $80 \%$ of dengue reported cases totaling 426,107 cases (Cunha et al. 1999).

The state of Piauí has an area of $252,378 \mathrm{~km}^{2}$ and the Atlantic Ocean forms the north border. The other frontiers include the states of Maranhão (W), Ceará and Pernambuco (E), Bahia and Tocantins (SW). The first case of dengue in Piauí were reported to be caused by DENV-2 in the capital, Teresina, mainly due to its geographic localization, around which the other states had already reported the presence of dengue (Figueiredo 1996). Afterwards, the number of reported cases has annually increased and, in 1998, a total of 14,626 cases were reported. In 1999, the reports dimished but in 2000, a period of high DENV activity was initiated and continued throughout the following years (Fig. 1).

Here, we show a laboratory investigation performed in Piauí between the years of 2000 and 2002 to study a virological surveillance program introduced in the state in order to support the epidemiological survey of the disease.

Serum samples were obtained from 535 outpatients with signs and symptoms of dengue fever at the Hospital of Infectious Disease located in Teresina, between 2000 and 2002. Before blood samples were taken for virological and serological procedures, patients filled out questionaries in order to have their personal knowledge on the disease and its prevention evaluated.

Virus isolation was attempted in sera drawn from acute patients by inoculation into clone C6/36 of Aedes albopictus cells and virus isolates were typed by indirect fluorescent antibody test using serotype-specific 


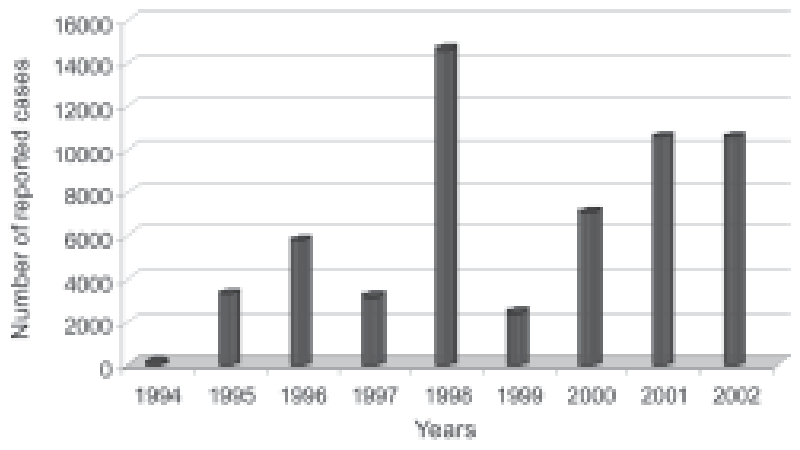

Fig. 1: dengue reported cases in the state of Piauí between 1994 and 2002 .

monoclonal antibodies (Gubler et al. 1984). Reverse transcription polymerase chain reaction (RT-PCR) was undertaken in order to obtain a rapid diagnostic for virological surveillance. Viral RNAs were extracted from acute sera using a QIAamp Viral Mini Kit (Qiagen, Inc., Valencia, CA) according to the manufacturer's protocol. RT-PCR for detecting and typing dengue viruses was carried out according to Lanciotti et al. (1992). IgM capture enzymelinked immunosorbent assay (MAC-ELISA) was performed for routine serodiagnosis using serotype-specific antigens mixture as described previously (Kuno et al. 1987).

Laboratorial findings showed that DENV isolation was obtained in 10 out of $46(21.7 \%)$ acute serum samples inoculated into $\mathrm{C} 6 / 36$ cell line. The virus types identified were DENV-1 $(n=2)$ and DENV-2 $(n=8)$. RT-PCR detected $48 \%$ of DENV (61/128), being 39 DENV-1, 19 DENV-2 and 3 DENV-3 (Fig. 2). Those DENV-3 cases confirmed by RT-PCR were the first DENV-3 cases reported in the state of Piauí marking the introduction of that new serotype in the state on May 2002. MAC-ELISA was positive in 111 $(30.7 \%)$ dengue cases out of 362 tested. The distribution of studied cases according to gender and age showed that age ranged from 4 to 80 years old (average 34 ) and there was no difference in the occurrence of dengue fever between men or women. Signs and symptoms of all cases were characterised of dengue fever.

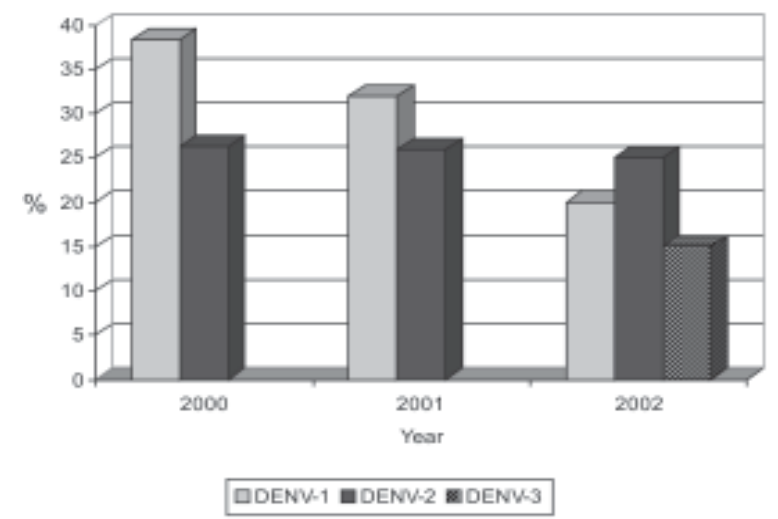

Fig. 2: percentage of dengue serotypes detected by virus isolation and/or reverse transcriptase polymerase chain reaction, state of Piauí, 2000 to 2002.
After the introduction of DENV-3 in the American continent in 1994, Anonymus (1995) repeated warnings about the risk of the DENV-3 introduction in Brazil have emphasized the priority to creat a dengue virus sur-veillance system in order to early detect its introduction. Indeed, DENV-3 was introduced in December 2000 through the state of Rio de Janeiro and favorable conditions for dengue transmission allowed the rapid spread of this new serotype to 22 out of 27 Brazilian Federal Units in 2002 (www.funasa.gov.br). In 2002, the implementation of RT-PCR in Piauí as a rapid diagnosis method played a definitive role to the surveillance system, notifying local authorities about the confirmation of the first DENV-3 cases in the state allowing the development of immediate control measures.

The evaluation of questionaries revealed that 352 (71.3\%) patients knew about the disease and that $45 \%$ (223/496) are aware about the involvement of the mosquito vector. The understanding whether water $(43.1 \%)$ or mosquitoes $(44.8 \%)$ are responsible for dengue transmission is still not clear, although they understand that prevention depends on measures of vector control, which includes the elimination of all containers holding water.

While an efficient vaccine is still not available, sustainable mosquito control involving the community and epidemiological laboratory-based surveillance are the best strategies to prevent dengue epidemic, diminishing the social and economic impact of disease (Gubler et al. 1989). Unfortunately our results on the population knowledge about dengue transmission showed that the authorities should coordinate campaigns on public health education to explain people about the need of community participation. In fact campaigns promoting personal responsibility should be a priority in the state.

\section{REFERENCES}

Anonymus 1995. Dengue 3 in Central America. Dengue Surveillance. Summary. San Juan, Puerto Rico. Division of Vector-Borne Infectious Diseases (CDC) 70: 4 pp.

Cunha RV, Schatzmayr HG, Miagostovich MP, Barbosa AM, Paiva FG, Miranda RM, Ramos CC, Coelho JC, dos Santos FB, Nogueira RM 1999. Dengue epidemic in the State of Rio Grande do Norte, Brazil, in 1997. Trans $R$ Soc Trop Med Hyg 93: 247-249.

Figueiredo LTM 1996. Dengue in Brazil I: history, epidemiology, and research. Virus Rev \& Res 1: 9-16.

Gubler DJ 1989. Surveillance for dengue and dengue hemorrhagic fever. Bull PAHO 23: 397-404.

Gubler DJ 1998. Dengue and dengue hemorrhagic fever. Clin Microbiol Rev 11: 480-496.

Gubler DJ 2002. Epidemic dengue/denguehemorrhagic fever as a public health, social, and economic problem in the $21 \mathrm{st}$ century. Trends Microbiol 10: 100-103.

Gubler DJ, Kuno G, Sather GE, Velez M, Oliver A 1984. Mosquito cell cultures and specific monoclonal antibodies in surveillance for dengue viruses. Am J Trop Med Hyg 33: 158-165.

Kuno G, Gomez I, Gubler DJ 1987. Detecting artificial antidengue IgM immune complexes using an enzyme-linked immunosorbent assay. Am J Trop Med Hyg 36:153-159.

Lanciotti RS, Calisher CH, Gubler DJ, Chang GJ, Vorndam AV 1992. Rapid detection and typing of dengue viruses from clinical samples by using reverse transcriptase-polymerase 
chain reaction. J Clin Microbiol 30: 545-551.

Nogueira RM, Miagostovich MP, de Filippis AM, Pereira MA, Schatzmayr HG 2001. Dengue virus type 3 in Rio de Janeiro, Brazil. Mem Inst Oswaldo Cruz 96: 925-926.

Nogueira RM, Miagostovich MP, Lampe E, Souza RW, Zagne SM, Schatzmayr HG 1993. Dengue epidemic in the stage of Rio de Janeiro, Brazil, 1990-1: cocirculation of dengue 1 and dengue 2 serotypes. Epidemiol Infect 111: 163-170.

Nogueira RMR, Miagostovich MP, Schatzmayr HG 2002. Dengue virus in Brazil. Dengue Bull 26: 1-10.
Pinheiro FP, Corber SJ 1997. Global situation of dengue and dengue hemorrhagic fever and its emergence in the Americas. World Health Statistics Quartely 50: 161-169.

Zagne SM, Alves VG, Nogueira RM, Miagostovich MP, Lampe E, Tavares W 1994. Dengue haemorrhagic fever in the state of Rio de Janeiro, Brazil: a study of 56 confirmed cases. Trans $R$ Soc Trop Med Hyg 88: 677-679.

World Health Organization 1997. Dengue Haemorrhagic Fever: Diagnosis, Treatment, Prevention, and Control, 2nd ed., Geneva. 